\title{
The First Korean Family with Hemoglobin-M Milwaukee-2 Leading to Hereditary Methemoglobinemia
}

\author{
Dae Sung Kim, Hee Jo Baek ${ }^{1,2}$, Bo Ram Kim , Bo Ae Yoon ${ }^{1,2}$, Jun Hyung Lee ${ }^{3}$, and Hoon Kook ${ }^{1,2}$ \\ ${ }^{1}$ Department of Pediatrics, Chonnam National University Hwasun Hospital, Hwasun; \\ ${ }^{2}$ Department of Pediatrics, Chonnam National University Medical School, Gwangju; \\ ${ }^{3}$ Department of Laboratory Medicine, Chonnam National University Hwasun Hospital, Chonnam National University Medical School, \\ Gwangju, Korea.
}

\begin{abstract}
Hemoglobin $\mathrm{M}(\mathrm{HbM})$ is a group of abnormal hemoglobin variants that form methemoglobin, which leads to cyanosis and hemolytic anemia. HbM-Milwaukee-2 is a rare variant caused by the point mutation CAC $>$ TAC on codon 93 of the hemoglobin subunit beta $(H B B)$ gene, resulting in the replacement of histidine by tyrosine. We here report the first Korean family with HbM-Milwaukee-2, whose diagnosis was confirmed by gene sequencing. A high index of suspicion for this rare Hb variant is necessary in a patient presenting with cyanosis since childhood, along with methemoglobinemia and a family history of cyanosis.
\end{abstract}

Key Words: Hemoglobin M-Milwaukee-2, methemoglobinemia, cyanosis, congenital hemolytic anemia

\section{INTRODUCTION}

Hemoglobinopathy refers to abnormalities in hemoglobin $(\mathrm{Hb})$, and more than 1300 variants thereof have been described. ${ }^{1}$ Hemoglobin $\mathrm{M}(\mathrm{HbM})$ is a group of abnormal Hb variants that form methemoglobin (metHb), leading to cyanosis and hemolytic anemia. ${ }^{2}$ MetHb is an altered state of $\mathrm{Hb}$ in which the heme iron is oxidized from the ferrous ( $\mathrm{Fe} 2+)$ to the ferric state (Fe3+). Since the ferric heme of MetHb does not bind with $\mathrm{O}_{2}$ and the remaining ferrous heme groups have an increased affinity to $\mathrm{O}_{2}$, the release of oxygen to the tissues is reduced. $^{3-5}$

In a healthy individual, metHb is spontaneously formed by auto-oxidation of $\mathrm{Hb}$ at a slow rate. ${ }^{6}$ However, metHb is maintained at a low level of approximately $1 \%$ by the metHb reduc-

Received: September 11, 2020 Accepted: October 8, 2020

Corresponding author: Hee Jo Baek, MD, PhD, Department of Pediatrics, Chonnam National University Hwasun Hospital, Chonnam National University Medical School, 322 Seoyang-ro, Hwasun 58128, Korea.

Tel: 82-61-379-7695, Fax: 82-61-379-7697, E-mail: swan93@naver.com

-The authors have no potential conflicts of interest to disclose.

(C) Copyright: Yonsei University College of Medicine 2020

This is an Open Access article distributed under the terms of the Creative Commons Attribution Non-Commercial License (https://creativecommons.org/licenses/ by-nc/4.0) which permits unrestricted non-commercial use, distribution, and reproduction in any medium, provided the original work is properly cited. tion pathway. ${ }^{6}$ Methemoglobinemia occurs when metHb levels exceed $1.5 \%$ in blood. ${ }^{7}$ Hereditary methemoglobinemia is often caused by methemoglobin reductase enzyme deficiency, rare $\mathrm{HbM}$ disease, or the rarest cytochrome $b_{5}$ deficiciency. ${ }^{7}$

$\mathrm{HbM}$ disease is caused by select variants in the $\alpha-, \beta-$, or rarely, $\gamma$ - globin genes. ${ }^{1,8}$ Among the 13 known variants of $\mathrm{HbM}$, HbM-Milwaukee- 2 is rare and is caused by a point mutation of CAC $>\mathrm{TAC}$ on codon 93 of the hemoglobin subunit beta $(H B B)$ gene, resulting in the replacement of histidine by tyrosine. ${ }^{7-14} \mathrm{In}$ this study, we describe the first Korean family with HbM-Milwaukee-2, whose diagnosis was confirmed by gene sequencing.

\section{CASE REPORT}

A 16-year-old girl was referred to our hospital for cholecystectomy due to gallstones. Her face and lips appeared cyanotic; however, there was no tachypnea or dyspnea. There was no history of cardiopulmonary illness or exposure to drugs and chemicals. Physical examination revealed no clubbing of fingers and toes and no organomegaly. No abnormality was found on chest auscultation.

Her mother and two brothers showed similar cyanosis. Furthermore, there was a history of lifelong cyanosis in many of her maternal family members (Fig. 1A and B). Her younger broth- 
er had a history of stone removal in the common bile duct.

Peripheral arterial oxygen saturation $\left(\mathrm{SpO}_{2}\right)$ on pulse oximetry was $35 \%$ at room air, which did not improve with administration of oxygen. Her, her mother's, and her older brother's arterial blood was dark chocolaty in color, similar to the color of venous blood (Fig. 1C). However, the patient's arterial blood gas analysis showed normal findings: arterial partial pressure of oxygen $\left(\mathrm{PaO}_{2}\right)$ of $115 \mathrm{~mm} \mathrm{Hg}$, arterial partial pressure of carbon dioxide $\left(\mathrm{PaCO}_{2}\right)$ of $34.5 \mathrm{~mm} \mathrm{Hg}$, and arterial oxygen saturation $\left(\mathrm{SaO}_{2}\right)$ of $92.9 \%$. Laboratory investigations showed findings consistent with hemolytic anemia (Table 1). Peripheral blood smear showed anisocytosis, poikilocytosis, and increased reticulocytes. Chest radiography, electrocardiography, and echocardiography findings were normal. Pulmonary disease was excluded by chest CT and pulmonary function test. Glucose-6-phosphate dehydrogenase activity was normal. The blood MetHb concentration was 13.0\% (normal range, 0-1.5\%), leading to the suspicion of hereditary methemoglobinemia.

$\mathrm{Hb}$ electrophoresis at alkaline $\mathrm{pH}$ revealed increased $\mathrm{HbF}$ (5.7\%) and an abnormal band (10.5\%) between $\mathrm{HbF}$ and $\mathrm{HbA} 2$ (Fig. 2A). For further evaluation of this unknown band, we analyzed the $H B B$ gene sequence by polymerase chain reaction
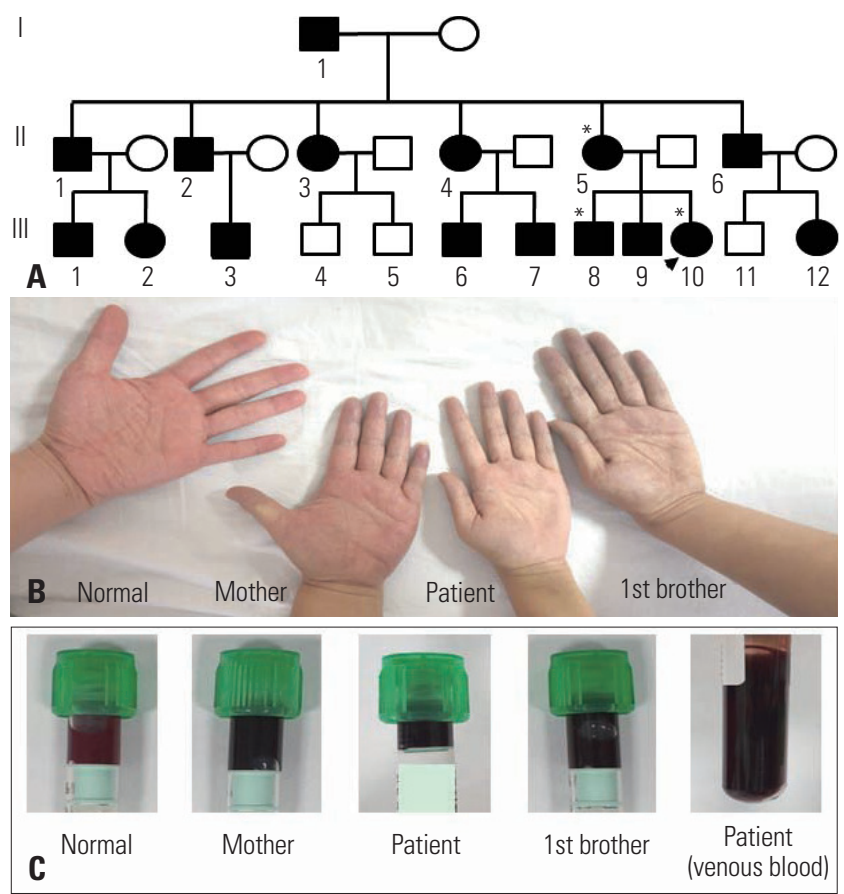

Fig. 1. Family tree of the patient's maternal family with a history of lifelong cyanosis and skin color and arterial blood color in the patient's family. (A) Black symbols indicate clinically affected family members. The arrowhead indicates the proband with the HBB variant and asterisk (*) indicates family members who were genetically confirmed. (B) Cyanotic skin color of the patient, her mother, and 1st brother compared to that of a normal healthy person. (C) Patient, her mother, and 1st brother's arterial blood had dark brown color compared to the bright red color in a normal healthy person. Of note, the patient's arterial blood color is almost the same as the color of her venous blood. HBB, hemoglobin subunit beta. and direct sequencing. This revealed a heterozygous point mutation of HBB gene (c277C $>$ T, p.His93Tyr) confirming HbMMilwaukee-2 (Fig. 2B).

Laboratory findings in her family members were similar (Table 1). The patient's mother (II-5 in Fig. 1A) and brother (III8 in Fig. 1A) had unknown bands on Hb electrophoresis, which were $13.6 \%$ and $16.8 \%$, respectively (Figures not shown). These unknown fractions were later attributed to HbM-Milwaukee-2 (Figures not shown).

The patient successfully underwent laparoscopic cholecystectomy for gallstones under monitoring of arterial oxygenation by co-oximetry.

Informed consent was obtained from the patients regarding the reporting and publication of this case report.

Table 1. Laboratory Findings and Oxygen Saturation on Pulse Oximetry in the Family Members with HbM-Milwaukee-2

\begin{tabular}{lcccccc}
\hline & Normal & Patient & Mother & $\begin{array}{c}\text { 1st } \\
\text { brother }\end{array}$ & $\begin{array}{c}\text { 2nd } \\
\text { brother }\end{array}$ \\
\hline Laboratory findings & & & & & \\
\hline Hemoglobin (g/dL) & $12-18$ & 10.9 & 11.4 & 12.9 & 12.5 \\
\hline $\mathrm{MCV}(\mathrm{fL})$ & $80-99$ & 94.9 & 101.9 & 97.9 & 99.0 \\
\hline $\mathrm{RDW}(\%)$ & $11.5-14.5$ & 15.3 & 15.4 & 14.9 & 14.4 \\
\hline Reticulocyte (\%) & $0.5-1.5$ & 4.15 & 5.25 & 3.52 & 2.45 \\
\hline Indirect bilirubin (mg/dL) & $0.3-1.0$ & 2.8 & 1.3 & 2.4 & 12.82 \\
\hline Haptoglobin (mg/dL) & $30-200$ & $<7.75$ & $<7.75$ & $<7.75$ & $<7.75$ \\
\hline Fetal hemoglobin (\%) & $0-2$ & 4.2 & - & - & - \\
\hline $\mathrm{Methemoglobin} \mathrm{( \% )}$ & $0.2-0.6$ & 13.0 & 6.0 & 6.3 & 13.1 \\
\hline Pulse oximetry & & & & & \\
\hline $\mathrm{SpO}_{2}$ (\%) & $96-100$ & 35 & 46 & 65 & 51 \\
\hline Arterial blood gas analysis & & & & & \\
\hline $\mathrm{SaO}_{2}$ (\%) & $92-98.5$ & 92.9 & 92.3 & 91.4 & 89.7 \\
\hline $\mathrm{PaO}_{2}$ (mm Hg) & $75-100$ & 115 & 117 & 113 & 97.3 \\
\hline
\end{tabular}

MCV, mean corpuscular volume; RDW, red blood cell distribution width $\mathrm{SpO}_{2}$, peripheral arterial oxygen saturation; $\mathrm{SaO}_{2}$, arterial oxygen saturation; $\mathrm{PaO}_{2}$, partial arterial pressure of oxygen.

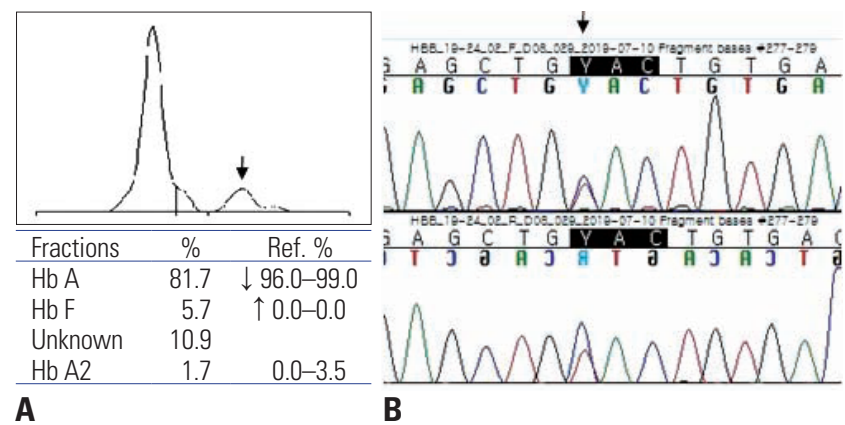

Fig. 2. Hb electrophoresis and $\beta$-globin gene sequencing of the patient's family. (A) The patient's $\mathrm{Hb}$ electrophoresis showed an unknown band (arrow) between $\mathrm{HbF}$ and $\mathrm{HbA} 2$, which was later revealed as $\mathrm{HbM}-\mathrm{Mil}-$ waukee-2. (B) The patient's $H B B$ gene sequencing revealed a heterozygous point mutation of CAC>TAC on codon 93, named as HbM-Milwaukee-2. Hb, Hemoglobin; HBB, hemoglobin subunit beta. 


\section{DISCUSSION}

Hemoglobinopathies are rare in Korea. However, the prevalence of thalassemia in young Koreans is recently increasing with the influx of immigrants from South-East Asia. ${ }^{15}$ A recent nationwide retrospective cohort study of hereditary hemolytic anemia (HHA) on the Korean pediatric population during 19972016 identified 369 children with HHA. ${ }^{16}$ Among them, hemoglobinopathies were seen in only 59 patients $(16 \%)$. Moreover, ${ }^{16}$ variants of $H B B$ gene mutations were identified in 28 Korean families; however, HbM-Milwaukee-2 was not reported. ${ }^{16}$

To date, this is the first report of Korean family with HbMMilwaukee-2, which was diagnosed by gene sequencing. HbMMilwaukee-2 was first identified as HbM-Hyde Park in an African-American in $1966 .{ }^{9}$ The same mutation was found in a Japanese patient with congenital cyanosis, and was named as HbM-Akita. ${ }^{10}$ Later, DNA sequence analysis revealed that the mutations in HbM-Milwaukee-2, HbM-Hyde Park, and HbMAkita were all the same. ${ }^{14}$

In this report, the affected members of the patient's maternal side had cyanosis without any other symptoms. Cyanosis did not improve with administration of oxygen. Their MetHb levels were between $6.0 \%$ and $13.1 \%$. The $\mathrm{SpO}_{2}$ on pulse oximetry was 35-65\%; however, $\mathrm{SaO}_{2}$ and $\mathrm{PaO}_{2}$ on arterial blood gas analysis were normal (Table 1).

Cyanosis with low $\mathrm{SpO}_{2}$ that does not improve with oxygen administration despite normal $\mathrm{PaO}_{2}$ and $\mathrm{SaO}_{2}$ are clues for the diagnosis of methemoglobinemia. The diagnosis of HbM disorders is challenging because of their low incidence and the absence of symptoms, except chronic cyanosis. ${ }^{13}$ However, the diagnostic method is relatively simple. Hb analysis by gel electrophoresis, as in our case, or high-performance liquid chromatography provides critical information with which to determine the presence of $\mathrm{Hb}$ variants. Furthermore, gene sequencing can confirm the $\mathrm{Hb}$ variants.

To date, all reported cases of HbM-Milwaukee-2 had heterogeneous trait. ${ }^{7-14}$ Homogeneity of the variant is thought to be fatal due to high levels of MetHb in the blood. ${ }^{13}$ The heterozygous variant is benign, and individuals with $\mathrm{HbM}$ disease have normal life expectancy and pregnancy. ${ }^{8}$ However, $H B B$ gene mutation, as seen in our case, can lead to acute hemolytic anemia, which can aggravate during stressful medical conditions, such as gastrointestinal infection or sepsis. ${ }^{8}$ Although there is no specific treatment, avoidance of oxidant drugs and toxins, such as aniline derivatives, nitrates, and other agents that form metHb, is recommended.

A high index of suspicion for this rare $\mathrm{Hb}$ variant is necessary in patients who present with chronic cyanosis since childhood, along with methemoglobinemia and a family history of cyanosis. Early genetic diagnosis can help in preventing unnecessary examinations and invasive procedures, in implementing preventive measures, and in providing genetic counseling to patients.

\section{ACKNOWLEDGEMENTS}

This study was supported by a grant (HCRI 14 008-1) from Chonnam National University Hwasun Hospital Institute for Biomedical Science.

\section{AUTHOR CONTRIBUTIONS}

Conceptualization: Hee Jo Baek. Investigation: Dae Sung Kim and Hee Jo Baek. Supervision: Bo Ram Kim, Bo Ae Yoon, and Jun Hyung Lee. Writing_original draft: Dae Sung Kim. Writing—review \& editing: Hee Jo Baek and Hoon Kook. Approval of final manuscript: all authors.

\section{ORCID iDs}

Dae Sung Kim

Hee Jo Baek

Bo Ram Kim

Bo Ae Yoon

Jun Hyung Lee

Hoon Kook https://orcid.org/0000-0003-4060-3802 https://orcid.org/0000-0003-3830-8134 https://orcid.org/0000-0003-1262-0031 https://orcid.org/0000-0002-3028-7335 https://orcid.org/0000-0002-8682-3694 https://orcid.org/0000-0002-9135-5821

\section{REFERENCES}

1. HbVar: database of human hemoglobin variants and thalassemia mutation [accessed July 7, 2020]. Available at: http://globin.cse. psu.edu/globin/hbvar/.

2. Rehman HU. Methemoglobinemia. West J Med 2001;175:193-6.

3. Paul A, Chacko ST. Congenital methaemoglobinaemia diagnosed in an adolescent boy. BMJ Case Rep 2019;12:e228470.

4. Ward J, Motwani J, Baker N, Nash M, Ewer AK, Toldi G. Congenital Methemoglobinemia Identified by Pulse Oximetry Screening. Pediatrics 2019;143:e20182814.

5. Chan ED, Chan MM, Chan MM. Pulse oximetry: understanding its basic principles facilitates appreciation of its limitations. Respir Med 2013;107:789-99.

6. Faivre B, Menu P, Labrude P, Vigneron C. Hemoglobin autooxidation/oxidation mechanisms and methemoglobin prevention or reduction processes in the bloodstream. Literature review and outline of autooxidation reaction. Artif Cells Blood Substit Immobil Biotechnol 1998;26:17-26.

7. Schnedl WJ, Queissner R, Schenk M, Enko D, Mangge H. Hereditary methemoglobinemia caused by Hb M-Hyde Park (Hb M-Akita) (HBB:c.277C>T; p.His93Tyr). Wien Klin Wochenschr 2019;131: 381-4.

8. Smith-Whitley K, Kwiatkowski JL. Hemoglobinopathies. In: Kliegman RM, St. Geme JW, BlumNJ, ShahSS, editors. Nelson textbook of pediatrics. 21th ed. Philadelphia (PA): Elsevier; 2020. p. 2552-3.

9. Heller P, Coleman RD, Yakulis V. Hemoglobin M (Hyde Park): a new variant of abnormal methemoglobin in a Negro. J Clin Invest 1966;45:1021.

10. Shibata S, Miyaji T, Iuchi I, Oba Y, Yamamoto K. Amino acid substitution in hemoglobin Makita. J Biochem 1968;63:193-8.

11. Kazanets EG, Andreeva AP, Molchanova TP, Pronina LKh, Tokarev IuN. First cases of the detection of Hb Hyde Park in the Soviet Union. Gematol Transfuziol 1988;33:43-6.

12. Upadhye D, Koduri P, Tarakeshwari S, Mehta P, Surve R, Warang P, et al. $\mathrm{Hb} \mathrm{M}$ Hyde Park and $\mathrm{Hb} \mathrm{M}$ Boston in two Indian families - a rare cause of methaemoglobinemia. Int J Lab Hematol 2015;37: 
e40-3.

13. Loong TY, Chong DL, Jamal AR, Murad NA, Sabudin RZ, Fun LC. First reported case of Haemoglobin-M Hyde Park in a Malay family living in Malaysia. EXCLI J 2016;15:630-5.

14. Hutt PJ, Pisciotta AV, Fairbanks VF, Thibodeau SN, Green MM. DNA sequence analysis proves $\mathrm{Hb} \mathrm{M}$-Milwaukee-2 is due to betaglobin gene codon 92 (CAC $\rightarrow$ TAC), the presumed mutation of Hb M-Hyde Park and Hb M-Akita. Hemoglobin 1998;22:1-10.
15. Lee HJ, Shin KH, Kim HH, Yang EJ, Park KH, Kim MJ, et al. Increased prevalence of thalassemia in young people in Korea: impact of increasing immigration. Ann Lab Med 2019;39:133-40.

16. Shim YJ, Jung HL, Shin HY, Kang HJ, Choi JY, Hah JO, et al. Epidemiological Study of Hereditary Hemolytic Anemia in the Korean Pediatric Population during 1997-2016: a Nationwide Retrospective Cohort Study. J Korean Med Sci 2020;35:e279. 